\title{
Engineered protein nanodrug as an emerging therapeutic tool
}

\author{
Yuanxin $\mathrm{Li}^{1,2}$, Jing Sun ${ }^{3}$, Jingjing Li ${ }^{1}(\bowtie)$, Kai Liu $^{1,2,4}(\bowtie)$, and Hongjie Zhang ${ }^{1,2,4}$ \\ ${ }^{1}$ State Key Laboratory of Rare Earth Resource Utilization, Changchun Institute of Applied Chemistry, Chinese Academy of Sciences, Changchun \\ 130022, China \\ ${ }^{2}$ University of Science and Technology of China, Hefei 230026, China \\ ${ }^{3}$ Institute of Organic Chemistry, University of Ulm, Albert-Einstein-Allee 11, Ulm 89081, Germany \\ ${ }^{4}$ Department of Chemistry, Tsinghua University, Beijing 100084, China
}

(C) Tsinghua University Press 2022

Received: 3 October 2021 / Revised: 20 November 2021 / Accepted: 25 December 2021

\begin{abstract}
Functional proteins are the most versatile macromolecules. They can be obtained by extraction from natural sources or by genetic engineering technologies. The outstanding selectivity, specificity, binding activity, and biocompatibility endow engineered proteins with outstanding performance for disease therapy. Nevertheless, their stability is dramatically impaired in blood circulation, hindering clinical translations. Thus, many strategies have been developed to improve the stability, efficacy, bioavailability, and productivity of therapeutic proteins for clinical applications. In this review, we summarize the recent progress in the fabrication and application of therapeutic proteins. We first introduce various strategies for improving therapeutic efficacy via bioengineering and nanoassembly. Furthermore, we highlight their diverse applications as growth factors, nanovaccines, antibody-based drugs, bioimaging molecules, and cytokine receptor antagonists. Finally, a summary and perspective for the future development of therapeutic proteins are presented.
\end{abstract}

\section{KEYWORDS}

therapeutic proteins, nanodrug, genetic engineering, structural modification, therapeutic efficacy

\section{Introduction}

In the past decades, therapeutic proteins have been increasingly developed for treating certain diseases, such as cancer and immune disorders [1-3]. Since 2000, hundreds to thousands of patents related to therapeutic proteins have been publicized each year. In addition, the number of relevant publications was expanded from $\sim 16,000$ in 2000 to $\sim 95,000$ in 2020. The Food and Drug Administration (FDA) has recently approved over 230 protein-based drug formulations [4], while a quarter of them have been approved since 2011. Typical therapeutic proteins grouped according to their molecular types including antibodies, enzymes, cytokines, hormones, and interferons, were provided in Table 1. Therapeutic proteins are superior to small molecule drugs owing to their excellent biocompatibility, high binding selectivity, and specificity. However, the fast enzymatic degradation, renal clearance, and liver metabolism of protein drugs often lead to short half-lives and limited efficacy $[5,6]$. As a consequence, the intravenous (IV) or subcutaneous (SC) administration of protein drugs with frequent dosing is needed, which eventually affects patient compliance and therapeutic outcomes [2,7]. In addition, it is challenging to produce large quantities of therapeutic proteins owing to their limited physical and chemical stability, leading to high costs in the pharmaceutical industry. Therefore, the development of new strategies to improve therapeutic proteins' stability, efficacy, bioavailability, and productivity is urgently needed for clinical applications.

As the physicochemical and enzymatic instability of therapeutic proteins may complicate their nanoformulation process, nanoformulations of therapeutic proteins should be prepared in a moderate condition to avoid loss of bioactivity. Many efforts have been devoted in the past decades to address the issues in developing protein therapeutics nanoformulation $[8,9]$. With the advance of recombinant DNA technology, therapeutic proteins can be genetically fused to other proteins commonly used in nanoparticle formulation, such as albumin, elastin-like polypeptide (ELP), ferritin, and lipoprotein [10-13]. Protein nanoparticles can be produced in mild conditions without using toxic chemicals or organic solvents [11, 14-17]. Moreover, protein nanoparticles offer the advantages of biocompatibility and biodegradability. Post-translational modification by attaching the protein to polymers is another appealing strategy for long-acting formulation. Such modification is helpful to hide antigenic determinant of a protein and increases the overall size so that the nanodrug will not be cleared out quickly [18-20]. Additionally, a nanocarrier-mediated delivery platform has been developed for the controlled and sustained release of proteins, thus enabling longacting therapeutics formation.

Herein, we summarize recent advances for the nanoformulation and applications of therapeutic proteins. Different strategies for developing therapeutic proteins are presented, including bio-conjugation or genetic recombination, chemical modification, and nanocarrier encapsulation. We further highlight the diverse applications of long-acting protein therapeutics, such as growth factors, nanovacines, antibody-based drugs, fluorescent proteins (FPs), and cytokine receptor 
Table 1 Examples of therapeutic proteins grouped according to their molecular types ${ }^{\mathrm{a}}$

\begin{tabular}{|c|c|c|c|c|c|}
\hline \multicolumn{2}{|c|}{ Therapeutic proteins } & Description & Modification strategy & Half-life & Process \\
\hline \multirow{4}{*}{ Antibodies } & Rituximab & Chimeric murine/human mAb against CD20 & - & $0.8 \mathrm{~h}$ & In market \\
\hline & \multirow{2}{*}{$\begin{array}{c}\text { Abciximab } \\
\text { Certolizumab } \\
\text { pegol }\end{array}$} & $\begin{array}{l}\text { Glycoprotein IIb/IIIa receptor inhibitor, Fab fragment of the chimeric } \\
\text { murine/human mAb }\end{array}$ & - & $10-30 \mathrm{~min}$ & In market \\
\hline & & PEGylated Fab antibody fragment against TNF- $\alpha$ & PEGylation & $\sim 14$ days & In market \\
\hline & JS016 & Recombinant human anti-SARS-CoV-2 mAb & - & N.A. & Phase 2 \\
\hline \multirow{3}{*}{ Enzymes } & Pegaspargase & PEGylated L-asparagine amidohydrolase & PEGylation & N.A. & In market \\
\hline & Pegloticase & PEGylated procine-like uricase & PEGylation & $\sim 14$ days & In market \\
\hline & TAK-062 & Computationally designed synthetic endopeptidase & Chemosynthesis & N.A. & Phase 2 \\
\hline \multirow{6}{*}{ Hormones } & Insulin lispro & Analogue of human insulin with reversed amino acid residues & Genetic engineering & $1 \mathrm{~h}$ & In market \\
\hline & $\begin{array}{l}\text { Insulin } \\
\text { glargine }\end{array}$ & Analogue of human insulin, forming microprecipitates at $\mathrm{pH} 7.4$ & $\begin{array}{l}\text { Genetic engineering, self- } \\
\text { assembly }\end{array}$ & $\begin{array}{l}30 \mathrm{~h} \text { in } \\
\text { cells }\end{array}$ & In market \\
\hline & Insulin & Analogue of human insulin, fused to fatty acid & Lipidation & $\begin{array}{c}425 \pm \\
78 \mathrm{~min}\end{array}$ & In market \\
\hline & Albiglutide & Analogue of human GLP-1 & HSA fusion & $4-7$ days & In market \\
\hline & NNC126-0083 & PEGylated long-acting hGH & PEGylation & $47.6 \mathrm{~h}$ & Phase 1 \\
\hline & TV-1106 & Albumin-fused long-acting hGH & HSA fusion & $\sim 7$ days & Phase 3 \\
\hline \multirow{4}{*}{$\begin{array}{l}\text { Cytokines/antag } \\
\text { onists }\end{array}$} & Oprelvekin & Recombinant interleukin eleven (IL-11) & - & $6.9 \pm 1.7 \mathrm{~h}$ & In market \\
\hline & Etanercept & TNFR & Fc-fusion & $102 \pm 30 \mathrm{~h}$ & In market \\
\hline & Anakinra & Human interleukin-1 receptor antagonist (IL-1Ra) & - & $4-6 \mathrm{~h}$ & In market \\
\hline & ALX-0061 & Human interleukin-6 receptor agonist & HSA fusion & $\sim 158.4 \mathrm{~h}$ & Phase 2 \\
\hline \multirow{3}{*}{ Interferons } & $\begin{array}{l}\text { Peginterferon } \\
a-2 a\end{array}$ & PEGylated human interferon- $a$ 2a & PEGylation & $50-140 \mathrm{~h}$ & In market \\
\hline & Pegfilgrastim & PEGylated human G-CSF & PEGylation & $15-80 \mathrm{~h}$ & In market \\
\hline & - & PASylated human interferon- $\alpha 2 a$ & PASylation & $\begin{array}{c}2.64- \\
15.85 \mathrm{~h}\end{array}$ & $\begin{array}{l}\text { Preclinical } \\
\text { trail }\end{array}$ \\
\hline
\end{tabular}

${ }^{a}$ The protein drugs in the rows with grey backgrounds are in clinical/preclinical trails (https://clinicaltrials.gov), whereas the others are FDA-approved and have been introduced in the market (THPdb database).

antagonists. In the end, we give a summary and perspective for the future development of therapeutic proteins.

\section{Strategies for protein nanoformulation}

Nanoformulation is an appealing strategy to overcome challenges associated with protein drug therapy, such as short circulatory halflives, poor bioavailability, and high dosage. Various technologies have been proposed and tested for prolonging residence time and improving the therapeutic performance of proteins, including bioconjugation or genetic recombination, chemical modification, and nanocarrier encapsulation.

\subsection{Protein nanodrugs based on bio-conjugation}

Protein nanodrugs based on bio-conjugation are designed at the gene level. The genetic engineering leads to the development of recombinant therapeutic proteins that contain functional domains with specific activities and other domains that can decrease immunogenicity or oligomerize to create structure, including albumin, ELP, and antibody Fc fragment. Coupled with the increased protein sizes, the recombinant therapeutic proteins exhibit slow systemic absorption and reduced kidney clearance rates, and can act for a longer time [21-23]. In contrast to chemical modified proteins, the genetically encoded synthesis endows recombinant therapeutic proteins with high monodispersity.

\subsubsection{Albumin}

Human serum albumin (HSA) is a globular protein containing approximately 585 amino acids and is abundant in plasma [17]. HSA exhibits excellent intrinsic properties such as biocompatibility, biodegradability, low immunogenicity, and nontoxicity. Therefore, it is widely utilized to develop the albuminconjugated drug [24]. The genes coding therapeutic protein can be fused to HSA genes by recombinant DNA technology, then expressed in bacterial, yeast, or mammalian systems, yielding the protein-albumin fusions. At present, albumin bioconjugated protein therapeutics, including glucagon-like peptide-1 (GLP-1), human growth hormone (hGH) (Table 1), and granulocyte colonystimulating factor protein (G-CSF), are available under preclinical/clinical trials [25-28]. Notably, the HSA-attached proteins showed a 10 to 1,000 times increase in plasma half-life [26].

\subsubsection{Antibody Fc fragment}

Another approach to extend therapeutic proteins' half-life utilizes a fragmented portion ( $\mathrm{Fc}$ region) of the immunoglobulin molecule [29]. Bioactive protein motifs can be incorporated into either terminus of the $\mathrm{Fc}$ region or inserted into the loop formation via recombinant DNA technology [30,31], thus prolonging half-life as the albumin-conjugated one. Furthermore, by taking advantage of the interaction between Fc and the FcRn receptor, the Fc-conjugated proteins bind to FcRn and undergo receptor-mediated endocytosis, which leads to enhanced absorption of therapeutic proteins and increases their effectiveness [32]. A considerable number of Fc-based protein therapeutics are available in the market and under pre-clinical/clinical trials, such as tumor necrosis factor receptor (TNFR) (Table 1) [33], vascular endothelial growth factor receptor (VEGFR) [34,35], and human granulocyte colony-stimulating factor (G-CSF) [36].

\subsubsection{Ferritin}

Ferritin is an iron storage protein for preventing cells from metal toxicity. It consists of 24 subunits and has a high molecular weight 
of $474 \mathrm{kDa}$ [11]. The 24 subunits self-assemble to form ferritin nanoparticles with both external and internal interfaces [37]. The unique structure of ferritin nanoparticles allows the protein cargoes to encapsulate in their inner cavity or display on their outer surface, showing the potential application in the field of therapeutic protein delivery. Deshpande et al. engineered a thermostable protein nanoparticle (tES) by utilizing the ferritins derived from Archaeoglobus fulgidus [38] (Fig. 1(a)). The genetic fusions of tES monomer and three divergent proteins, including green fluorescent protein (GFPuv), horseradish peroxidase (HRPc), and Renilla luciferase (rLuc), significantly improved expression productivity and stability. More importantly, recombinant proteins internalized by tES showed resistance to thermal, organic, chaotropic, and proteolytic denaturation and were released from the nanoassembly (Fig. 1(b)). Jeon et al. demonstrated promising peptide-ferritin nanoparticles by fusing the interleukin-4 receptor (IL-4R)-targeting peptide AP-1, with ferritin-L-chain (FTL) [39]. Due to the multivalent-binding capacity of the AP-1-ferritin nanoparticle, its avidity was increased by about $10^{6}$ fold compared with the AP- 1 peptide. Georgiev et al. developed nanovaccines by genetic fusion of HIV-1 antigen (Env) or influenza hemagglutinin antigen (HA) to ferritin [40]. Notably, a dual-antigen nanoparticle was designed via the combined assembly of Env-ferritin and HA-ferritin. The two-component ferritin nanoparticles elicited effective neutralizing antibody responses against the related viruses in guinea pigs. These results provided proof of principle for a general technology for multimeric presentation of protein therapeutics.

2.1.4 ELPS

ELPs are a family of genetically encoded biopolymers that contain repeats of canonical sequences derived from native elastin [41]. The primary structure of ELPs consists of repetitive pentapeptide units (VPGXG) ${ }_{n}$, with the $X$ residue being any amino acid except proline. As their similarity to natural elastin, ELPs show exceptional biocompatibility for in vivo applications. One specific property of ELPs is their thermosensitive phase transition behavior, termed lower critical solution temperature (LCST). More specifically, soluble forms of ELPs can be triggered to selfassemble into highly-ordered structures upon heating above the transitional point $\left(T_{\mathrm{t}}\right)[12]$. On the contrary, the thermosensitive ELPs remain hydrated in an aqueous solution below $T_{\mathrm{t}}$. The amino acid sequences of ELPs directly influence $T_{\mathrm{t}}$, and the in vivo aggregation properties can be altered genetically.

Consequently, ELPs can be genetically fused to other therapeutic proteins to fabricate thermo-responsive nanodrugs that retain their thermosensitive behavior [42]. Koria et al. demonstrated the fabrication of a fusion protein comprising ELPs and keratinocyte growth factor (KGF) [43]. This fusion protein preserved the characteristic ELPs inverse phase transitioning and self-assembled into nanoparticles at physiological temperatures. These nanoformulation drugs promoted keratinocyte and fibroblast proliferation and re-epithelialization and granulation in the diabetic wound model. Wang et al. engineered a fusion protein termed LSI, with a model mitogenic protein of lacritin fused at the $\mathrm{N}$-terminus of an ELP [44]. This LSI fusion protein underwent thermo-responsive assembly of nanoparticles at physiological temperatures and promoted faster corneal epithelium healing in mice models. More interestingly, the ELP-mediated assembly of LSI is essential for this potent activity. Although ELPs have attracted considerable attention as promising bio-engineering materials, their functional versatility can be further extended to (a)

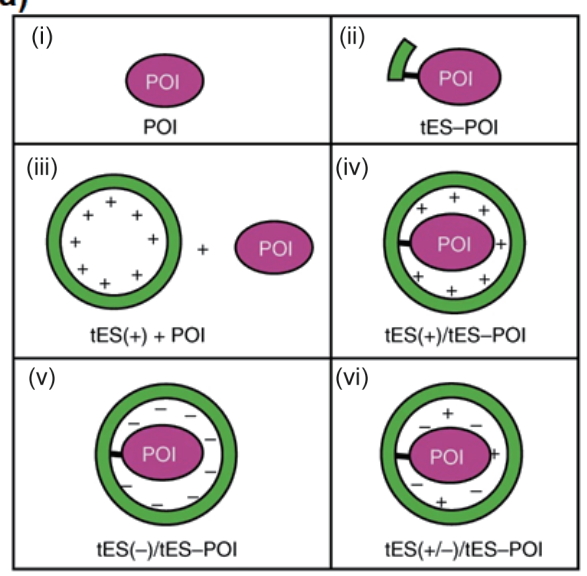

(c)

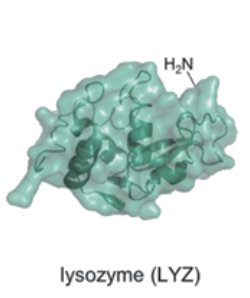

(b)
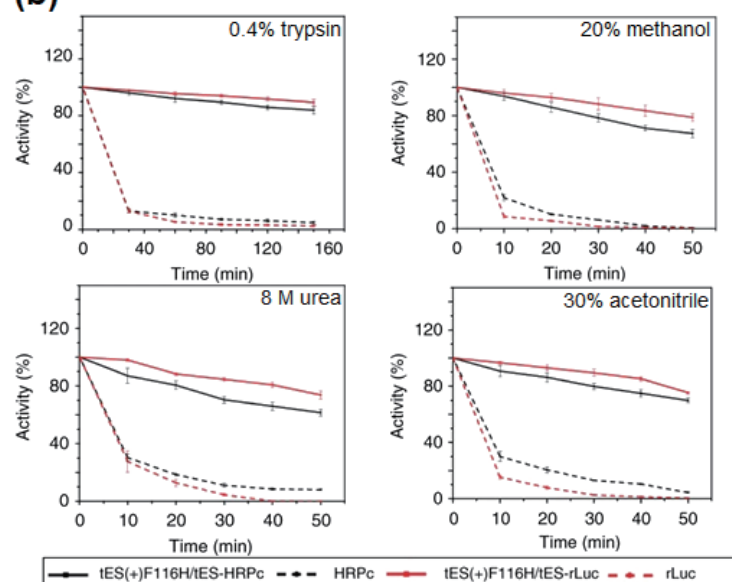

(d)

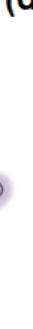

Figure 1 (a) Schematic for the fabrication of thermostable protein nanoparticles: (i) POI, protein of interest; (ii) thermostable exoshell-POI (tES-POI), POI fused to the C-terminus of a tES subunit; (iii) POI expressed in the presence of a tES shell but without encapsulation; (iv) and (vi) coexpression of tES-POI with tES(+), tES(-), and $\mathrm{tES}(+/-)$ shells. (b) The presence of tES enhanced the stability of $\mathrm{tES}-\mathrm{POI}$ in $0.4 \%$ trypsin, $20 \%$ methanol, $8 \mathrm{M}$ urea, and $30 \%$ acetonitrile. Mutation of tES from F116 to $\mathrm{H}$ resulted in a $\mathrm{pH}$-titratable assembly and dissociation. $\mathrm{tES}(+) \mathrm{F} 116 \mathrm{H}$ encapsulated the HRPc or rLuc that fused with tES. (a) and (b) Reproduced with permission from Ref. [38]. (c) Deshpande, S. et al. 2017. (c) Schematic representation for the fabrication of LYZ $\mathrm{mPEG}$ The surface modification of LYZ was performed by the reaction of MPEG with free amines on the surface of lysozyme. (d) Time-dependent analysis of bacteria growth; lysozyme-loaded nanoparticles showed better activity than free fluorescent-labeled lysozyme (Cy5-LYZ) at equivalent concentrations ( $0.32 \mu \mathrm{g} / \mathrm{mL}$ of payload). (c) and (d) Reproduced with permission from Ref. [47]. (c) WILEY-VCH Verlag GmbH \& Co. KGaA, Weimheim 2018. 
formulate therapeutic proteins. Other protein engineering and design strategies using both ELPs and synthetic polymers are also discussed in the following section.

\subsection{Protein nanodrugs based on chemical modification}

Apart from the bio-conjugation strategy, the therapeutic protein is often modified with various chemical moieties, including polyethylene glycol (PEG) and lipids. Unlike bio-conjugation, chemical modifications straightforward introduce synthetic polymers to therapeutic proteins through chemical reactions between the polymers and functional groups of protein residues. For example, peginterferon- $\alpha 2 \mathrm{a}$ was developed via the linkage of PEG moiety at a single site to the interferon- $\alpha$ moiety via a stable amide bond to lysine (Table 1). Chemical modification masks the protein molecules from enzymatic degradation and contributes to improved bioavailability $[45,46]$. As its non-toxic, nonimmunogenic, and hydrophilic characteristics, PEG is the most commonly used polymer for the chemical modification of therapeutic proteins. A variety of PEGylated therapeutic proteins are available in the market, such as interferon- $\alpha$, G-CSF, and procine-like uricase (Table 1). Moreover, PEGylated nanoparticle systems are becoming an increasingly important tool for protein and peptide drugs delivery. Steiert et al. reported that the nanoparticles comprised of mPEG-modified lysozymes ( $\left.\mathrm{LYZ}_{\mathrm{mPEG}}\right)$ (Fig. 1(c)) [47]. The LYZ mPEG $_{\text {nanoassemblies allowed }}$ encapsulation of a large hydrophilic payload, and the obtained nanoformulations successfully showed antimicrobial activity against the gram-positive bacteria strain M. Luteus (Fig. 1(d)). Ackerman and coworkers reported the development of a novel PEGylated peptide (R321). The R321 peptide could self-assemble into uniform nanoparticles, essentially protecting itself from proteolytic degradation and improving pharmacokinetics (PKs) [48].

Recently, our laboratory reported an attractive strategy to improve the in vivo stability and efficacy of proteins. A new type of highly charged ELPs manufactured by genetic engineering was presented. After genetically fusing to target proteins, the resulting protein conjugates can electrostatically combine with PEG molecules, forming well-defined nanoassembly $[49,50]$. Remarkably, these nanoassemblies offer enhanced stability, bioavailability, and high drug loading capacity, which show great potential for cancer and rheumatoid arthritis (RA) therapy. In addition to PEG molecules, lipids have been widely used to develop protein nanodrugs due to their ability to deliver hydrophilic and hydrophobic payloads and high cell permeability. Recently, Gao's team developed a general method to construct biomimetic nanocarriers comprised of apolipoprotein E (ApoE) and synthetic lipids [51,52]. The nanocarriers exhibited both blood-brain barrier permeability and A $\beta$-targeting ability, providing a promising platform for brain drug delivery toward treating Alzheimer's disease (AD). Kim et al. developed a nanoparticle composed of lipid (DOTAP/DOPE) and apolipoprotein 1 (APOA-I) [53]. Protein drugs (cytochrome C) were conjugated with a membrane-permeable sequence (MPS) peptide and non-covalently incorporated into the surface of DOPE/DOTAP nanoparticles. The nanoformulation successfully mediated the targeted delivery and effective penetration of protein drugs into non-small cell lung tumors.

\subsection{Protein nanodrugs based on versatile delivery systems}

In contrast to directly modifying therapeutic proteins' pharmacokinetic parameters by bio-conjugation and chemical modification, nanomaterials-mediated delivery systems could also be used to produce long-acting therapeutic proteins. Protein delivery systems incorporate the target protein into a matrix or depot and contribute to the slow and sustained release of the protein payload in the circulatory system, thereby extending the half-life and circulation time. Extensive review articles have summarized the advances in synthetic polymer-based delivery systems. Therefore we will focus on nanomaterials from natural or recombinant proteins here. As a drug delivery system, protein nanoparticles have advantages like biodegradability, low toxicity, versatile surface modification, and easy particle size control [6,38, $47,49,51-53]$. Many kinds of natural proteins can be used to fabricate delivery platforms, including albumin, fibroin, gelatin, and collagen.

\subsubsection{HSA and bovine serum albumin (BSA)}

To enhance the cell-penetrating ability and stability of $\beta$ galactosidase, researchers developed a nanoplatform consisting of $30 \mathrm{Kc19}$ protein and HSA [54]. 30Kc19 exhibits anti-apoptotic, cellpenetrating, and enzyme-stabilizing abilities. Thus, 30Kc19-HSA nanoparticles had superior cellular uptake and intracellular stability when compared with HSA nanoparticles. The BSA can also be applied to produce protein delivery micelles. Jiang et al. prepared a PEGylated negatively charged BSA protein, which could load positively charged lysozyme proteins termed Spry1 [55]. Condensation of Spryl within the PEGylated albumin improved the stability and anticancer efficacy of the Spryl, leading to lowered half-maximal inhibitory concentration $\left(\mathrm{IC}_{50}\right)$ value against the breast cancer cells and effective growth inhibition of three-dimensional MCF-7 tumor spheroids.

\subsubsection{Silkfibroin}

Fibroin is the main protein that exists in silk fibers. Due to its low immunogenicity, biodegradability, mechanical strength, significant productivity, and low cost, fibroin is an attractive material for nanoparticle generation [11,56-58], especially for vehicles of sensitive biologicals such as insulin and growth factors. Kundu et al. reported the fabrication of silk fibroin spherical nanoparticles as depots for VEGF [59]. These nanoparticles can accumulate in the cytosol of murine squamous cell carcinoma cells and support a 3week sustained release of VEGF. Similarly, bone morphogenetic protein-2 (BMP-2) encapsulated by silk fibroin particles was also proved to have elevated stability and bioactivity [60]. In addition, silk protein has been studied as a vector for enzyme transportation, such as glucose oxidase, superoxidase, $\beta$ glucosidase, L-asparaginase, and Pin1 isomerase [61]. Kim et al. developed cationic lipid-coated fibroin nanoparticles to deliver Pinl isomerase, a peptidyl-prolyl cis-trans isomerase that plays a critical role in osteoblast differentiation [62]. This fibroin-lipid nanocarrier delivered Pin1 with high efficiency and low cytotoxicity, resulting in the recovery of osteoblast differentiation in Pin1-deficient cells.

\subsubsection{Lipoprotein}

Lipoproteins are natural nanoparticles that transport lipid molecules such as cholesterol and fatty acids within the body. Due to its non-immunogenic, biocompatible, biodegradable, and $A \beta$ targeting properties, lipoproteins have become increasingly attractive for drug delivery, especially in treating $\mathrm{AD}$ [51]. Huang et al. designed a nanostructure termed monosialotetrahexosylganglioside-modified reconstituted high density lipoprotein (GM1-rHDL) by combining the lipoprotein ApoE and GM1-1,2-dimyristyl-sn-glycero-3-phosphocholine (DMPC) liposome [63]. The GM1-rHDL as a flexible nanoplatform showed an average particle size of about $25 \mathrm{~nm}$ and was able to load neuroprotective peptide aNAP. aNAP-GM1- 

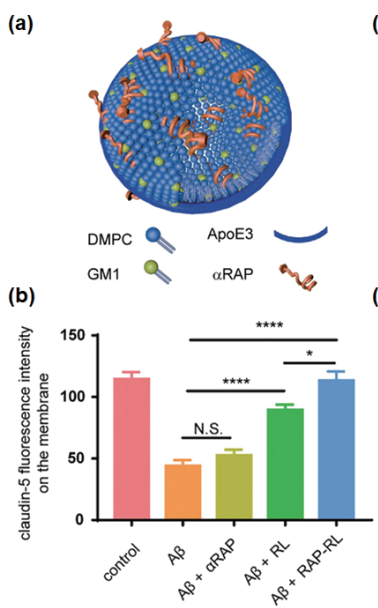

(c)

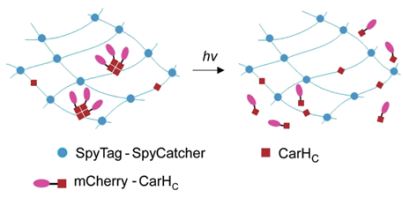

(d)

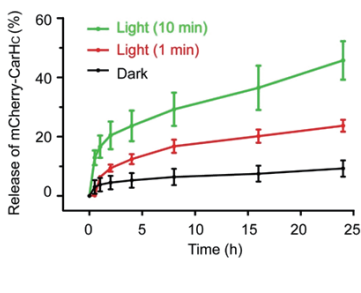

Figure 2 (a) Schematic diagram shows the structure and components of RAPRL. (b) Quantification of claudin-5 fluorescence intensity on the cell membrane $(n=5)$. bEnd. 3 cells or BV2 cells were pretreated with A $\beta$ for $18 \mathrm{~h}$ and then incubated with RAP-RL, RL, or aRAP for $18 \mathrm{~h}$. (a) and (b) Reproduced with permission from Ref. [64]. ๑ Zhang, Q. et al. 2020. (c) Schematic showing the immobilization and release of the mCherry-C-terminal adenosylcobalamin binding domain $\left(\mathrm{CarH}_{\mathrm{C}}\right)$ protein. $\mathrm{CarH}_{\mathrm{C}}$ tetramerization leads to the mCherry immobilization into the hydrogel in the dark. The disassembly of tetrameric $\mathrm{CarH}_{\mathrm{C}}$ by light facilitates the release of $\mathrm{mCherry-CarH}_{\mathrm{C}}$ (d) Release profiles of mCherry-CarH $\mathrm{C}_{\mathrm{C}}$ from the hydrogels subjected to 0,1 , and $10 \mathrm{~min}$ of white light exposure. The percentage release of mCherry was calculated based on the total amount of mCherry added into the gel. Error bars show SDs from three independent measurements. (c) and (d) Reproduced with permission from Ref. [67]. () National Academy of Sciences 2017.

rHDL significantly reduced $A \beta$ deposition and rescued the memory loss in the $\mathrm{AD}$ mice model, which was more effective than both $\alpha$ NAP solution and GM1-rHDL alone.

Similarly, this team further developed another nanoplatform (RAP-RL) constituted with GM1-DMPC, ApoE, and an antagonist peptide (RAP) of the receptor for advanced glycation end-products (RAGE) (Fig. 2(a)) [64]. The RAP-RL displayed a nanodisc structure where the RAP peptides are often incorporated into the surface (Fig. 2(a)). The RAP-RL efficiently reversed the transfer of claudin-5 from the cell membrane to the cytoplasm induced by $A \beta$ treatment and alleviated $A \beta$-induced tight-junction impairment (Fig. 2(b)). The integrity and function of neurovascular units in $\mathrm{AD}$ model mice were regained, and cognitive abilities were improved through the synergistic effect of RAP-RL. The nanocarriers prepared here with recombinant lipoprotein and commercially available synthetic lipids have good biocompatibility and are more easily scalable and reproducible. On this basis, these works provide a promising nanoplatform for $\mathrm{AD}$ treatment by delivering protein drugs through lipoprotein nanoparticles.

\subsubsection{Otherproteins}

Wang et al. exploited glutaraldehyde (GA) crosslinked gelatin nanomaterials that can deliver multiple growth factors (basic fibroblast growth factor (bFGF) and BMP-2) in a controlled manner [65]. Notably, the modulation of the growth factor's release kinetics was realized by changing the degree of crosslinking. It provides a novel and convenient dual delivery approach for the slow and sustained release of therapeutic proteins. The photoresponsive protein termed $\mathrm{CarH}_{\mathrm{C}}$ [66] generated a stimuli-responsive "smart" hydrogel using genetically encoded SpyTag-SpyCatcher chemistry under mild physiological conditions [67]. The $\mathrm{CarH}_{\mathrm{C}}$ hydrogel was able to encapsulate and release the fluorescent protein of mCherry in a light-dependent manner (Fig. 2(c)). The release of $m_{C h e r r y-C a r H}$ in this system can be readily controlled by adjusting the light irradiation time
(Fig. 2(d)). This study presents a versatile strategy for designing stimuli-responsive materials that allow for dynamically tunable drug administration.

\section{Long-acting protein nanodrugs for diverse applications}

The nanoformulations of therapeutic proteins help maintain drug efficacy and stability over time and thus have shown great potential in different aspects, including bioimaging, diagnosis, disease intervention, and therapy.

\subsection{Growth factor}

A growth factor is a kind of multi-effect peptide that regulates cell growth and other cell functions through binding to specific, highly compatible cell membrane receptors. Growth factors generally show a short retention time, usually a few hours in vivo [4], which needs to be extended to achieve the desired efficacy. Bessa et al. created the nanoparticles by thermoresponsive self-assembly of elastin-like polymer (VPAVG) 220 for delivery of BMPs [68]. These BMPs could be efficiently encapsulated and released in a sustained way for 14 days. The activity of BMPs was retained, as demonstrated by the induction of alkaline phosphatase activity and osteogenic mineralization in $\mathrm{C} 2 \mathrm{Cl} 2$ cells. In addition to both growth factors alone, the combined release of BMP-2 and BMP-14 exhibited high bioactivity. This work potentially paves the way for developing multifunctional carriers for the delivery of growth factors.

Furthermore, growth factors can be displayed on the surface of nanoparticles by fusion with the protein carrier. By genetically fusing the epidermal growth factor (EGF) to the C-terminus of a bacteriophage capsid protein $\mathrm{Q} \beta$, Finn and coworkers developed virus-based nanoparticles displaying 5 to 12 copies of EGF on their exterior surface [69]. Additionally, the nanoparticle-displayed EGF promoted auto-phosphorylation of the EGF receptor and apoptosis of A431 cells, demonstrating the bioactivity of nanoparticle-displayed EGF. Interestingly, the EGF-displayed nanoparticles could be valuable carriers for the targeted delivery of therapeutic agents [70].

Through genetic recombination, it is possible to effectively integrate two or more antigenic proteins to improve the potency and breadth of vaccines. Therefore, nanoparticle immunogens codisplayed four kinds of haemagglutinins have been fabricated [76]. The nanoparticles induced broadly protective antibody responses against different heterologous viruses, even in the presence of antigenic mismatches in the hypervariable head domain. To improve the protective breadth and lower the off-target risk of influenza vaccine, Deng et al. fabricated bilayer protein nanoparticles via desolvating tetrameric influenza matrix protein 2 ectodomains (M2e) into protein nanoparticle cores and encapsulating these cores by crosslinking partial domains of HAs (Fig. 3(c)) [77]. As shown in Fig. 3(d), these protein nanoparticles elicited solid and broad immune activities to various HA antigens. In addition, self-assembling virus-like particles have been developed as valuable tools for cancer immunotherapy [78, 79]. All these findings suggested the great potential of self-assemble protein nanoplatforms for clinical applications.

\subsection{Nanovaccine}

The successful applications of nanotechnology hold great promise for the development of nanovaccines. Compared with the traditional vaccines, nanovaccine offers several advantages, including high antigen-loading efficiency, enhanced efficacy, and stability [71]. Here, we introduce several kinds of nanovaccines which have been developed for the prevention of infectious disease 
(a)

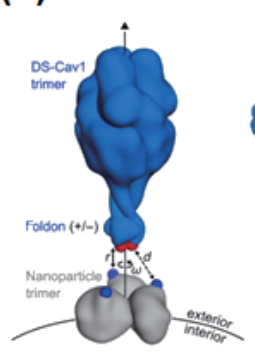

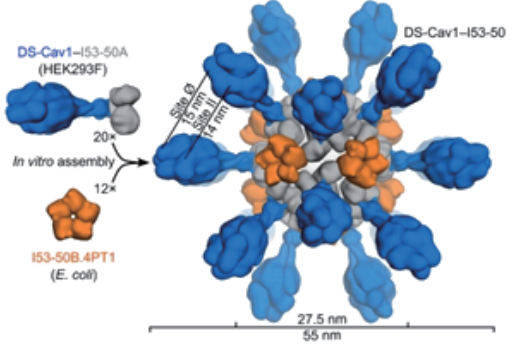

(b)

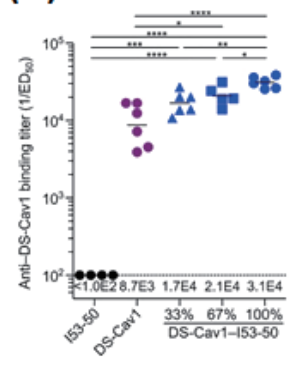

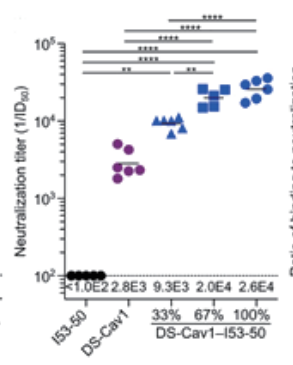

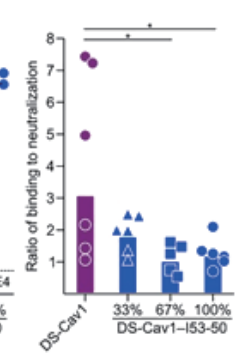

(c)

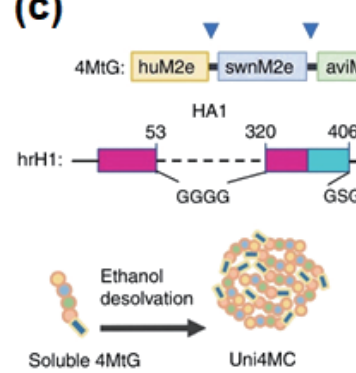

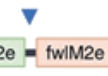

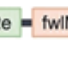

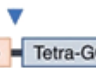
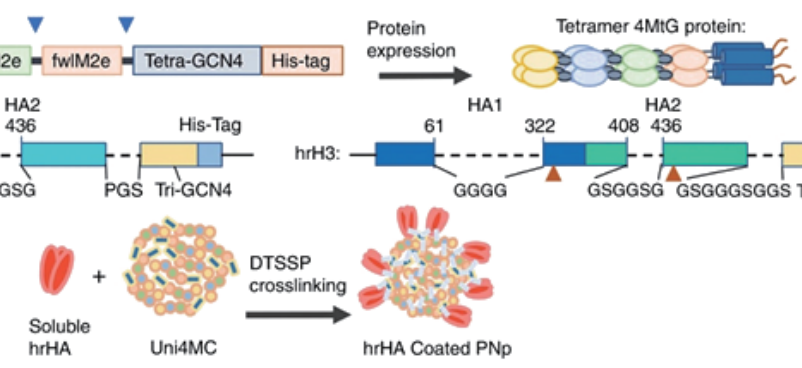

(d)

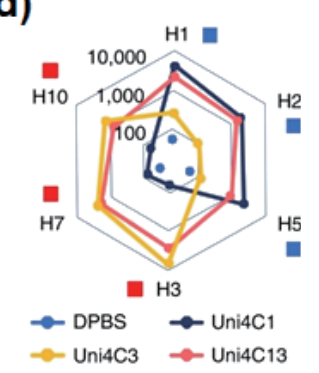

Figure 3 (a) Structural model of prefusion-stabilized variant of the F glycoprotein trimer (DS-Cav1, left) and DS-Cav1-I53-50 (right). (b) DS-Cav1-specific binding antibody titers (left) from mice immunized with I53-50, trimeric DS-Cav1, or DS-Cav1-I53-50 nanoparticle immunogens at the indicated valency. Serum neutralizing antibody titers (middle) induced by each immunogen, plotted as in the left figure. The ratio of DS-Cavl-binding to neutralizing antibody titers (right), derived from the data in left and middle. (a) and (b) Reproduced with permission from Ref. [75]. (c) Marcandalli, J. et al. 2019. (c) Cartoon models (upper) of the construction and expression of recombinant proteins $4 \mathrm{MtG}, \mathrm{hrH1}$, and $\mathrm{hrH}$. Tetrameric $\mathrm{M} 2 \mathrm{e}$ (4MtG) was formed by four types of M2e, HA stalk domains comprised of designed $\mathrm{hrH1}$ and hrH3. Schematic diagram (lower) of Uni4MC (desolvated 4MtG nanoparticles) fabrication and double-layered nanoparticle generation. An additional layer of trimeric hrHA proteins was crosslinked onto the desolvated Uni4MC nanoparticles surface via DTSSP (sulfosuccinimidyl propionate) crosslinking. (d) Radar diagram depicting breadth of immune serum binding to HA subtypes, the binding activities of immune sera to H1, H2, H5, H7, and H10 were tested. Uni4C13 (a cocktail of Uni4C1 and Uni4C3) elicited broadly reactive to various HA antigens. (c) and (d) Reproduced with permission from Ref. [77]. (c) Deng, L. et al. 2018.

or cancer therapy. The self-assembled peptide nanoparticles [72] were used to produce a severe acute respiratory syndrome (SARS) nanovaccine [73], which repetitively displays the SARS B-cell epitope $\mathrm{HRC1}$ at the exterior surface. Immunization experiments revealed the infection-inhibition activity of these peptide nanoparticles. This work represents a promising platform for nanovaccine design, particularly for diseases characterized by neutralizing epitopes [14]. Nabel and coworkers designed a selfassembled nanoparticle vaccine by genetically fusing viral hemagglutinin to the $\mathrm{N}$-terminus of ferritin [74], which improves the efficacy and breadth of influenza virus immunity compared to commercially available influenza vaccines [74]. Marcandalli et al. designed a protein nanoparticle vaccine for a respiratory syncytial virus (RSV) via in vitro assembly of computationally designed recombinant proteins [75]. The RSV surface F glycoprotein termed DS-Cav1 was fused to the computationally designed protein I53-50A, generating DS-Cav1-I53-50A (Fig. 3(a)). Afterward, the highly ordered nanoparticle immunogens were formed, driven by the assembly of DS-Cav1-I53-50A with another pentameric protein, I53-50B (Fig. 3(a)). As shown in Fig. 3(b), the nanovaccine induced approximately 10 -fold higher neutralizing antibody responses than the trimeric DS-Cavl. This work offers new opportunities for structure-based vaccine design.

\subsection{Antibody-based therapeutics}

Therapeutic antibodies, especially monoclonal antibodies (mAbs), as the most abundant and the fastest-growing groups of protein therapeutics, are being gradually improved for efficacy, safety and cost. Here, new engineered antibody therapeutic formats are introduced, including nanobides (Nbs), antibody fragement nanoasemblies and antibody-drug conjugates (ADCs). By engineering antibody variable (Fv) regions, many antibody fragments were achieved, such as single-chain variable fragments (scFv) and Nbs. Unlike traditional full-length antibodies, these antibody fragments are small ( $15 \mathrm{kDa}$ for Nbs), highly soluble, lowly susceptible to steric hindrances and amenable to rapid and low-cost microbial production. Recently, a viarety of Nbs have been in preclinical/clinical development for diseases such as brain cancer, inflammation disorder and viral infection [80,81]. Shi and coworkers discovered an extensive repertoire of robust neutralizing $\mathrm{Nbs}$ to SARS-CoV2 [82]. Moreover, the homotrimeric, multivalent $\mathrm{Nb}$ constructs $\left(\mathrm{IC}_{50}\right.$ as low as 0.058 $\mathrm{ng} / \mathrm{mL}$ ) were fabricated using tandem-repeat strategy and produced in a large scale from E. coli. These Nbs provided costeffective and efficacious therapeutics to combat the COVID-19 pandemic.

Another way to generate high-valency antibody constructs is to use polypeptide-mediated nanoassembly of antibody fragments [83]. Antibody fragments assembled through fusion with oligomerization domains, including ELPs, collagen-like polypeptides, albumin, transmembrane proteins, etc. Compared with multivalent constructs generated by consecutive conjugation, the polypeptide-mediated nanoassembly may address the instability of tandem-repeated antibody fragments. Alam et al. described a SpyCatcher/SpyTag based platform to construct trivalent anti-human epidermal growth factor receptor 3 (HER3) scFv [84]. As shown in Fig. 4(a), three anti-HER3 scFv fused SpyCatchers were ligated to one synthetic Tri-SpyTag peptide, generating a Tri-scFv construct. The HER3 affinity of the Tri-scFv was 12 times higher than that of the monovalent control. This study presents a promising platform for antibody assembly and multivalency.

Antibody-drug conjugates (ADCs) consist of recombinant mAbs that covalently bind to cytotoxic small-molecule drugs via 
(a)

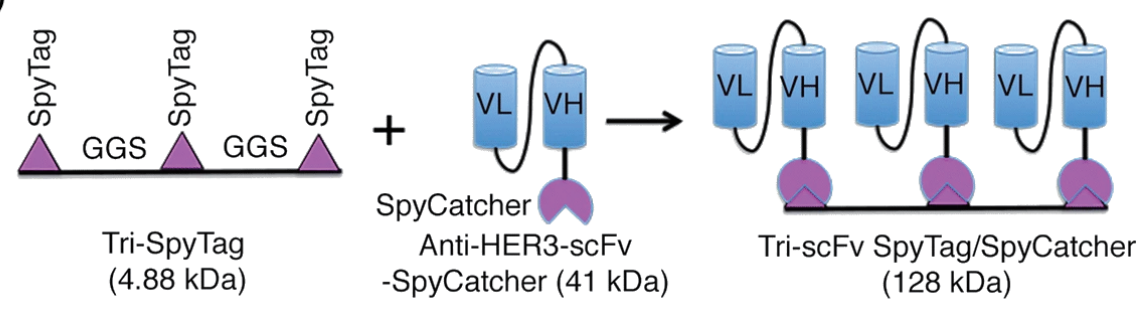

(b)

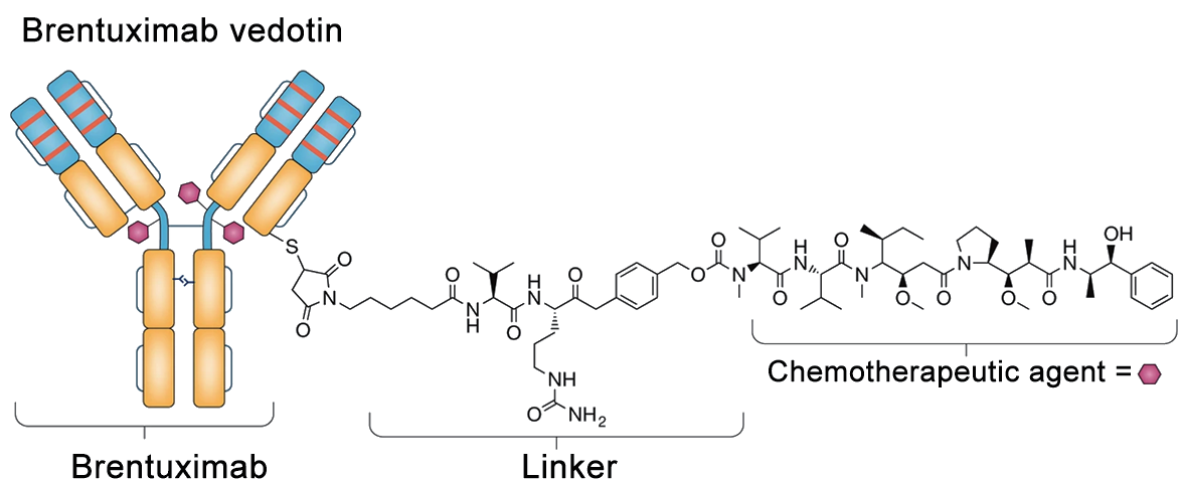

Figure 4 (a) Schematic representation for the fabrication of anti-HER3 scFv SpyCatcher/SpyTag construct. Reproduced with permission from Ref. [84]. ๑ Alam, M. K. et al. 2018. (b) The FDA-approved ADC brentuximab vedotin, comsisting of a chimeric IgG1 mAb specific for CD30, is attached to 4 monomethyl auristatin E (MMAE) moieties via a protease-cleavable linker. Reproduced with permission from Ref. [85]. ๑ Macmillan Publishers Limited, part of Springer Nature 2017.

synthetic linkers (Fig. 4(b)), combining the antitumor activities of chemotherapeutic agents with the high selectivity and preferred pharmacokinetics of mAbs [85]. Although only two ADCs, brentuximab vedotin and trastuzumab emtansine, have been approved by FDA, there are more than 60 ADCs in clinical trials. Major future directions for ADCs are to explore the best target antigens, appropriate chemotherapeutic agents as well as optimized linkers. Specifically, the incorporation of $\mathrm{pH}$-sensitive [86] or photo-sensitive [87] linkers into ADCs allows rapid and controllable drug detachment, providing new opportunities for reducing toxicities to normal tissues while improving therapeutic efficacy.

\subsection{Fluorescent protein}

Fluorescent proteins have been widely used as markers for imaging cells and tissues treated by gene transfection, especially for non-invasive and quantitative visualization of tumor growth and metastasis in vivo [88]. However, limited transfection efficiency and lack of targeting ability restrict their clinical application. The development of FPs or derived materials, which can be directly applied for bio-imaging, represents a promising solution to these issues. Guan et al. reported an FP-based nanoparticle developed through the genetic fusion of the cell-penetrating peptides (CPPs) and enhanced green fluorescent protein (EGFP) [89]. The EGFP nanoparticle displayed high stability in mouse plasma and preferentially accumulated in the tumor after tail vein administration. As the GFPs suffer from the short tissuepenetration depth and high autofluorescence background, advanced near-infrared (NIR) FPs with excitation and emission maxima inside the NIR window have been developed [90]. Some genetically engineered NIR FPs show adequate high brightness, photostability, and signal-to-background ratio, such as mIFP [91]. Our group developed the mIFP-based nanoassemblies with NIR emission and outstanding photostability by electrostatic complexation between positively charged MIFP conjugates and anionic carboxylate-terminated $\mathrm{PEG}^{-\mathrm{COO}^{-}}$chains (Figs. 5(a)-5(c)) [49]. Remarkably, stable and long-time imaging of the tumor sites, including tumor xenografts and metastatic tumor nodules (Fig. 5(d)), was achieved through a single intravenous injection, overcoming the limitations of FP bioimaging that relies on gene transfection and rapid fluorescence decay. Inspired by this strategy, many other protein-based nanomaterials were successfully developed and applied to treat various diseases [50, 92-95].

\subsection{Receptor antagonist}

IL-1 receptor antagonists (IL-1Ra) modulate the IL-1 receptor signaling pathway, antagonize IL-1-induced secretion of inflammation mediators, downregulate the activity of matrix metalloproteinases (MMPs) [96], and are therefore regarded as an effective tool for blocking IL-1-induced inflammatory diseases. Particularly, recombinant IL-1Ra has been approved for RA (Table 1) [97]. However, daily injection of a high dose (100 mg daily) is usually required to maintain a therapeutic concentration of IL-1Ra due to its fast degradation in serum. As a consequence, researchers have exploited IL-1Ra depots that provide sustained drug release and desired bioefficacy. Shamji et al. genetically synthesized a fusion protein combining IL-1Ra and thermalresponsive ELPs [98]. The resulting fusion proteins aggregated through the thermal phase-transitioning behaviors of the ELP domains, thus forming an IL-1Ra-containing drug depot after orthotopic injection in vivo. Although the in vitro bioactivity of ELP-IL-1Ra is lower than that of the free IL-1Ra, ELP-IL-1Ra might provide a longer persistence time in the joint. Liu and coworkers developed and characterized supramolecular IL1-Ra nanoformulations with significantly improved efficiency for RA treatment (Fig. 6) [50]. As shown in Fig. 6(a), IL-1Ra was firstly fused to positively charged ELPs, then encapsulated into supramolecular assemblies via electrostatic complexation with PEG or chondroitin sulfate (CS), generating morphologically welldefined IL-1Ra nanoformulations. Significantly, these nanoformulations possessed a typical controlled release behavior (Fig. 6(b)) and offered strikingly increased half-life of $30 \mathrm{~h}$ and bioavailability of 7-times higher than pristine IL-1Ra (Figs. 6(c) and $6(\mathrm{~d})$ ). In the collagen-induced RA rat models, IL-1Ra nanoformulations showed extraordinary long-term antiinflammatory effects and robust bioefficacy for RA therapy 
(a) Plasmid of mIFP-K72

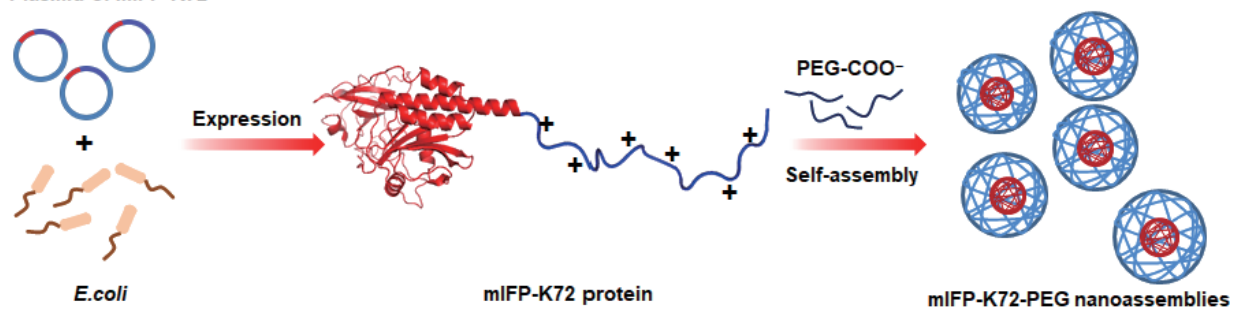

(b)

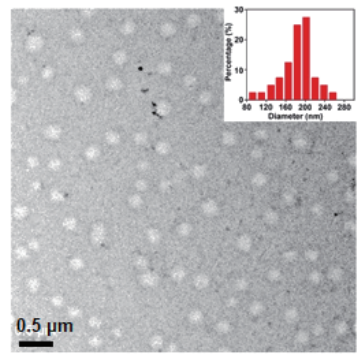

(c)

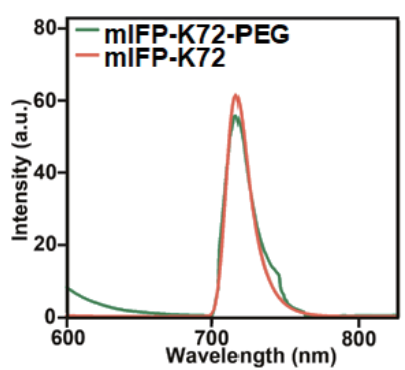

(d)

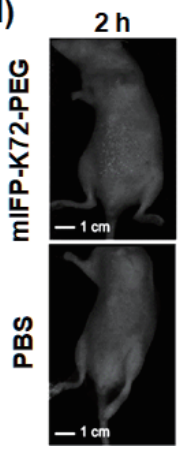

$12 \mathrm{~h}$

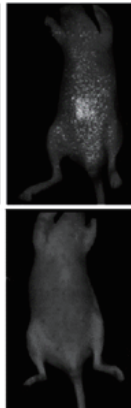

$24 \mathrm{~h}$

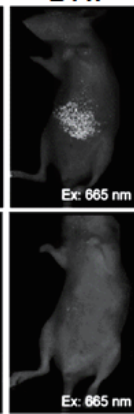

Figure 5 The synthesis and characterization of monomeric near-infrared fluorescent proteins (mIFP)-K72-PEG nanoassemblies. (a) Schematic representation for the fabrication of mIFP-K72-PEG assemblies. The protein mIFP-K72 was genetically fused with a cationic polypeptide of (VPGKG) 72 to the C-terminus of mIFP by recombinant DNA technology and expressed in Escherichia coli. By complexation with negatively charged anionic carboxylate-terminated poly(ethylene glycol) (PEG$\mathrm{COO}^{-}$), the mIFP-K72-PEG protein assemblies were produced. (b) TEM image and size distribution of the mIFP-K72-PEG. The protein assemblies exhibit a uniform spherical structure with an average size of about $200 \mathrm{~nm}$ in diameter. Scale bar: $0.5 \mu \mathrm{m}$. (c) Emission spectra of mIFP-K72 and mIFP-K72-PEG $\left(\lambda_{\mathrm{ex}}=680 \mathrm{~nm}\right)$. (d) In vivo NIR fluorescence imaging of mice with metastatic tumor nodules in the liver after administration of mIFP-K72-PEG (800 nmol/kg). PBS-treated as a control group. Scale bar: $1 \mathrm{~cm}$. (a)-(d) Reproduced with permission from Ref. [49]. @) WILEY-VCH Verlag GmbH \& Co. KGaA, Weinheim 2020.

(a)

\section{a)}
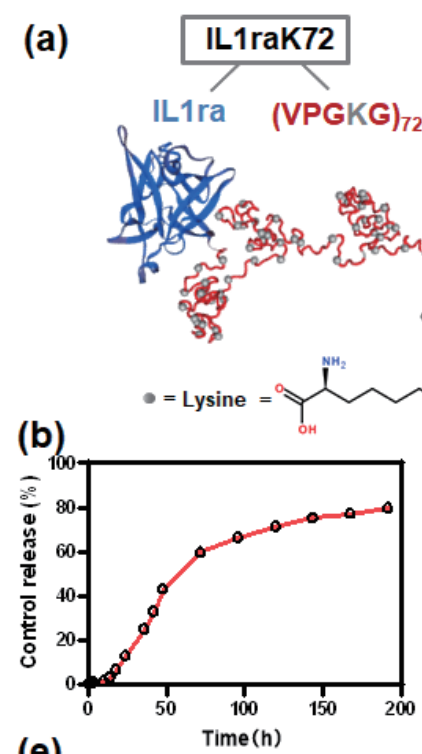

(e)

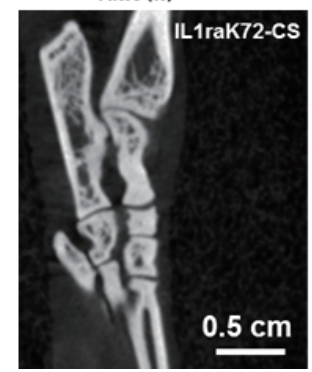

FDA-approved components (PEG or chondroitin sulfate)

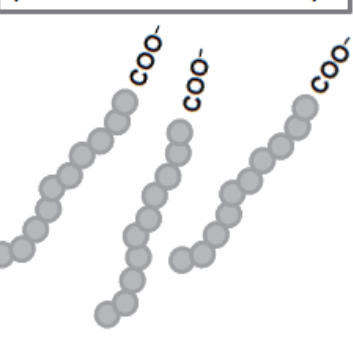

(c)

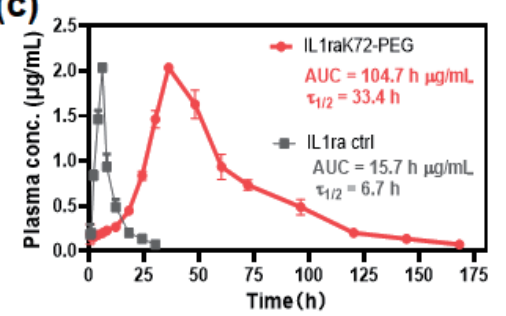

(d)
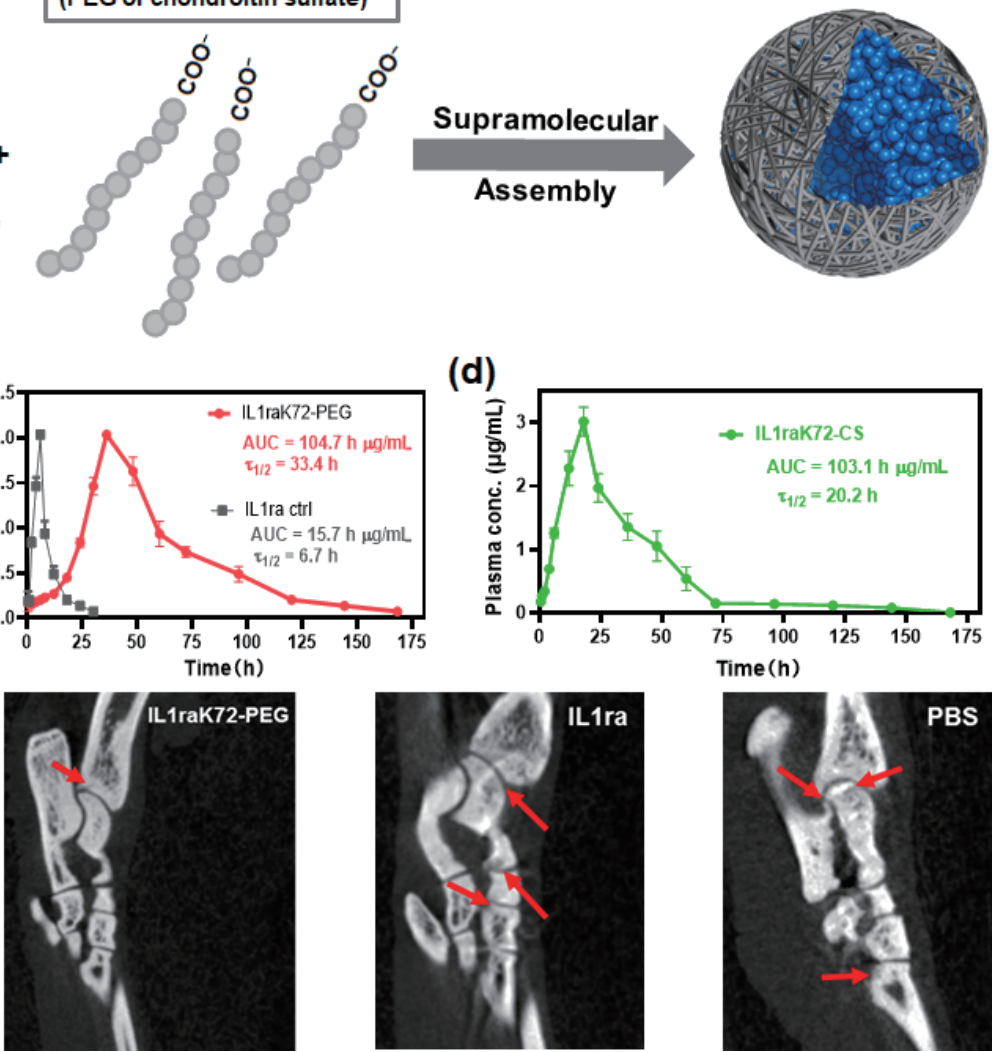

Figure 6 Schematic illustration and biological function of IL1ra nanotherapeutics systems. (a) Cationic IL1raK72 is complex with FDA-approved components, such as PEG or chondroitin sulfate via supramolecular assembly, leading to proteinaceous nanoparticles. The IL1raK72 molecule is recombinantly synthesized, including therapeutic IL1ra domain and random coil part $\left(\mathrm{VPGKG}_{72}\right.$. (b) Typical controlled release behavior of IL1ra from IL1raK72-PEG nanosystems in PBS. (c) In vivo plasma concentration profiles of IL1raK72-PEG nanoassembly demonstrate an ultralong retention behavior, especially compared with the non-functionalized IL1ra protein. (d) In vivo plasma concentration profiles of IL1raK72-CS nanoassembly show excellent bioavailability and half-life properties. (e) Representative microCT images of rat ankles treated with different approaches. The red arrows indicate rough surfaces and destructions of joints. (a)-(e) Reproduced with permission from Ref. [50]. ๑ Wiley-VCH GmbH 2021. 
(Fig. 6(e)), with smooth and intact morphology of the joints compared to destructions and damages of ankles in the PBS and IL-1Ra groups. The bioefficacy could maintain up to 14 days in RA rat models. This noncovalent assembly strategy via engineered chimeric protein and chemical modification might be adapted for other therapeutics to form long-acting formulations.

\subsection{Protein used for nanoparticle surface modification}

When administrated in vivo, nanoparticles inevitably contact with biomolecules in the physiological fluid, generating a "biomolecule corona" on the surface of nanoparticles [99]. This process dramatically influences the biological properties of the nanoparticles, including blood circulation lifetime, cellular uptake rate, bioavailability, and toxicity. Therefore, one way to improve nanoparticles' in vivo properties and achieve targeted drug delivery is to decorate the nanoparticles' surface. Albumin or albumin-binding moieties have been modified on the nanoparticle surface to achieve a better serum half-life. Azizi et al. developed albumin-coated silver nanoparticles (ASNPs) that showed high anti-cancerous activity in vivo [100], indicating that ASNPs could be a good candidate for nanomedicine. Chilkoti and coworkers reported an albumin-binding domain (ABD) conjugate of chemotherapeutic of doxorubicin (ABD-Dox), which showed significantly prolonged half-life than free Dox [101]. The 47-aa ABD was biosynthesized as an ELP-ABD fusion from microbial expression system, representing a promising candidate for nanomaterial modification. Wurm and coworkers found that clusterin (also known as apolipoprotein J) reduced non-specific cellular uptake of polymer-coated polystyrene nanoparticles [102]. In addition, protein-mediated nanoparticle surface modification is important for direct targeting to specific cells or tissues. Certain apolipoproteins are helpful in nanoparticles' transport over the blood-brain barrier (BBB) [51, 63, 64, 103]. Recently, Chen et al. achieved the first NIR-II photoacoustic imaging-guided therapy nanoplatform of RA [104]. Polymer nanoparticles for NIR-II photoacoustic molecular imaging were conjugated with therapeutic mAb tocilizumab (TCZ) with RA therapeutic and targeting functions to develop mAb-coated TCZ-PNPs that confer RA-targeted imaging and therapy.

\section{Conclusions and perspectives}

Therapeutic proteins are essential tools for the effective therapy of various diseases, and in certain situations, they are irreplaceable. We have reviewed the progress of protein-based nanodrugs over the past decades. Strategies for extending the half-life and stability of therapeutic proteins are highlighted, including bio-conjugation via genetic engineering, chemical modification, and nanosystem delivery. Moreover, we have summarized the achievements in exploring functional nanoformulations of proteins for disease diagnosis and treatment. Therapeutic proteins are endowed with improved stability, biocompatibility bioavailability, and bioefficacy by nanoformulations, significantly reducing the treatment costs and improving patient compliance.

Despite all the advances made, challenges remain in the development of protein nanomedicines. For example, the efficacy reproducibility of protein nanomedicines needs to be addressed. In this context, the development of highly robust and facile synthetic approaches is needed. Especially, the physical and chemical properties of engineered protein should be considered for nanoformulation. Computational-aided methods can be applied extensively to select the optimal protection sites in the nanoformulation process. In addition, new synthetic strategies for therapeutic proteins are needed to realize large-scale and low-cost production. In this context, the development of novel synthetic biology tools that can facilitate the expression systems, including bacterial, yeast, or mammalian cells, can be an efficient choice to pave the way. Furthermore, novel nanoplatforms that enable the integration of proteins and small molecule drugs might be a promising way to establish a new paradigm for collaborative therapy.

\section{Acknowledgements}

This research was supported by the National Key Research and Development Program of China (Nos. 2020YFA0908900, 2018YFA0902600, and 2020YFA0712102), the National Natural Science Foundation of China (Nos. 21877104, 21834007, 22107097, 21878258, 22020102003, and 22125701), K. C. Wong Education Foundation (No. GJTD-2018-09), and the Youth Innovation Promotion Association of the Chinese Academy (CAS, No. 2021226).

\section{References}

[1] Johnson-Léger, C.; Power, C. A.; Shomade, G.; Shaw, J. P.; Proudfoot, A. E. Protein therapeutics-lessons learned and a view of the future. Expert Opin. Biol. Ther. 2006, 6, 1-7.

[2] Wen, F.; Rubin-Pitel, S. B.; Zhao, H. Engineering of therapeutic proteins. In Protein Engineering and Design. Park, S. J.; Cochran, J. R. Eds.; CRC Press: Boca Raton, 2009; pp 153-177.

[3] Cheng, L.; Yang, L.; Meng, F. H.; Zhong, Z. Y. Protein nanotherapeutics as an emerging modality for cancer therapy. $A d v$. Healthc. Mater. 2018, 7, 1800685.

[4] Usmani, S. S.; Bedi, G.; Samuel, J. S.; Singh, S.; Kalra, S.; Kumar, P.; Ahuja, A. A.; Sharma, M.; Gautam, A.; Raghava, G. P. S. THPdb: Database of FDA-approved peptide and protein therapeutics. PLoS One 2017, 12, e0181748.

[5] Werle, M.; Bernkop-Schnürch, A. Strategies to improve plasma half life time of peptide and protein drugs. Amino Acids 2006, 30, 351-367.

[6] Zaman, R.; Islam, R. A.; Ibnat, N.; Othman, I.; Zaini, A.; Lee, C. Y.; Chowdhury, E. H. Current strategies in extending half-lives of therapeutic proteins. J. Control. Release 2019, 301, 176-189.

[7] Bajracharya, R.; Song, J. G.; Back, S. Y.; Han, H. K. Recent advancements in non-invasive formulations for protein drug delivery. Comput. Struct. Biotechnol. J. 2019, 17, 1290-1308.

[8] Wang, S. Y.; Duan, Y. O.; Zhang, Q. Z.; Komarla, A.; Gong, H.; Gao, W. W.; Zhang, L. F. Drug targeting via platelet membranecoated nanoparticles. Small Struct. 2020, 1, 2000018.

[9] Kozlowski, H. N.; Mohamed, M. A. A.; Kim, J.; Bell, N. G.; Zagorovsky, K.; Mubareka, S.; Chan, W. C. W. A Colorimetric test to differentiate patients infected with influenza from COVID-19. Small Struct. 2021, 2, 2100034.

[10] Nguyen, V. H.; Lee, B. J. Protein corona: A new approach for nanomedicine design. Int. J. Nanomed. 2017, 12, 3137-3151.

[11] Hong, S. Y. N.; Choi, D. W.; Kim, H. N.; Park, C. G.; Lee, W.; Park, H. H. Protein-based nanoparticles as drug delivery systems. Pharmaceutics 2020, 12, 604.

[12] Zhang, N.; Mei, K.; Guan, P.; Hu, X.; Zhao, Y. L. Protein-based artificial nanosystems in cancer therapy. Small 2020, 16, 1907256.

[13] Corchero, J. L.; Vázquez, E.; García-Fruitós, E.; Ferrer-Miralles, N.; Villaverde, A. Recombinant protein materials for bioengineering and nanomedicine. Nanomedicine (Lond) 2014, 9 , 2817-2828.

[14] Uzunalli, G.; Guler, M. O. Peptide gels for controlled release of proteins. Ther. Deliv. 2020, 11, 193-211.

[15] Sandra, F.; Khaliq, N. U.; Sunna, A.; Care, A. Developing proteinbased nanoparticles as versatile delivery systems for cancer therapy and imaging. Nanomaterials (Basel) 2019, 9, 1329.

[16] Ferrer-Miralles, N.; Rodríguez-Carmona, E.; Corchero, J. L.; García-Fruitós, E.; Vázquez, E.; Villaverde, A. Engineering protein self-assembling in protein-based nanomedicines for drug delivery and gene therapy. Crit. Rev. Biotechnol. 2015, 35, 209-221.

[17] Hassanin, I. A.; Elzoghby, A. O. Self-assembled non-covalent protein-drug nanoparticles: An emerging delivery platform for anti- 
cancer drugs. Expert Opin. Drug Deliv. 2020, 17, 1437-1458.

[18] Yang, Y. Y.; Chen, Q. L.; Lin, J. Y.; Cai, Z.; Liao, G. C.; Wang, K.; Bai, L.; Zhao, P.; Yu, Z. Q. Recent advance in polymer based microspheric systems for controlled protein and peptide delivery. Curr. Med. Chem. 2019, 26, 2285-2296.

[19] Patra, J. K.; Das, G.; Fraceto, L. F.; Campos, E. V. R.; RodriguezTorres, M. D. P.; Acosta-Torres, L. S.; Diaz-Torres, L. A.; Grillo, R.; Swamy, M. K.; Sharma, S. et al. Nano based drug delivery systems: Recent developments and future prospects. $J$. Nanobiotechnol. 2018, 16, 71.

[20] Flintegaard, T. V.; Thygesen, P.; Rahbek-Nielsen, H.; Levery, S. B.; Kristensen, C.; Clausen, H.; Bolt, G. N-glycosylation increases the circulatory half-life of human growth hormone. Endocrinology 2010, 151, 5326-5336.

[21] Strohl, W. R. Fusion proteins for half-life extension of biologics as a strategy to make biobetters. BioDrugs 2015, 29, 215-239.

[22] Beals, J. M.; Shanafelt, A. B. Enhancing exposure of protein therapeutics. Drug Discov. Today Technol. 2006, 3, 87-94.

[23] Ekladious, I.; Colson, Y. L.; Grinstaff, M. W. Polymer-drug conjugate therapeutics: Advances, insights and prospects. Nat. Rev. Drug Discov. 2019, 18, 273-294.

[24] Feng, L. D.; Yang, L.; Li, L. J.; Xiao, J. Y.; Bie, N. N.; Xu, C.; Zhou, J.; Liu, H. M.; Gan, L.; Wu, Y. Z. Programmed albumin nanoparticles regulate immunosuppressive pivot to potentiate checkpoint blockade cancer immunotherapy. Nano Res. 2022, 15, 593-602.

[25] Kontermann, R. E. Half-life extended biotherapeutics. Expert Opin. Biol. Ther. 2016, 16, 903-915.

[26] Sleep, D. Albumin and its application in drug delivery. Expert Opin. Drug Deliv. 2015, 12, 793.

[27] Cohen-Barak, O.; Sakov, A.; Rasamoelisolo, M.; Bassan, M.; Brown, K.; Mendzelevski, B.; Spiegelstein, O. Safety, pharmacokinetic and pharmacodynamic properties of TV-1106, a long-acting GH treatment for GH deficiency. Eur. J. Endocrinol. 2015, 173, 541-551.

[28] Santagostino, E.; Martinowitz, U.; Lissitchkov, T.; Pan-Petesch, B.; Hanabusa, H.; Oldenburg, J.; Negrier, C.; Pabinger, I.; Prondzinski, M. V. D.; Altisent, C. et al. Long-acting recombinant coagulation factor IX albumin fusion protein (rIX-FP) in hemophilia B: Results of a phase 3 trial. Blood 2016, 127, 1761-1769.

[29] Shi, Y. N.; Sun, X. F.; Zhang, L. P.; Sun, K. X.; Li, K. K.; Li, Y. $\mathrm{X}$; Zhang, Q. Fc-modified exenatide-loaded nanoparticles for oral delivery to improve hypoglycemic effects in mice. Sci. Rep. 2018, 8,726 .

[30] Jazayeri, J. A.; Carroll, G. J. Fc-based cytokines: Prospects for engineering superior therapeutics. BioDrugs 2008, 22, 11.

[31] Pridgen, E. M.; Alexis, F.; Kuo, T. T.; Levy-Nissenbaum, E.; Karnik, R.; Blumberg, R. S.; Langer, R.; Farokhzad, O. C. Transepithelial transport of Fc-targeted nanoparticles by the neonatal fc receptor for oral delivery. Sci. Transl. Med. 2013, 5, 213 ra167.

[32] Liu, L. M. Pharmacokinetics of monoclonal antibodies and Fcfusion proteins. Prot. Cell 2018, 9, 15-32.

[33] Nestorov, I.; Zitnik, R.; DeVries, T.; Nakanishi, A. M.; Wang, A.; Banfield, C. Pharmacokinetics of subcutaneously administered etanercept in subjects with psoriasis. Br. J. Clin. Pharmacol. 2006, $62,435-445$.

[34] Wells, J. A.; Glassman, A. R.; Ayala, A. R.; Jampol, L. M.; Bressler, N. M.; Bressler, S. B.; Brucker, A. J.; Ferris, F. L.; Hampton, G. R.; Jhaveri, C. et al. Aflibercept, Bevacizumab, or Ranibizumab for diabetic macular edema: Two-year results from a comparative effectiveness randomized clinical trial. Ophthalmology 2016, 123, 1351-1359.

[35] Rath, T.; Baker, K.; Dumont, J. A.; Peters, R. T.; Jiang, H. Y.; Qiao, S. W.; Lencer, W. I.; Pierce, G. F.; Blumberg, R. S. Fc-fusion proteins and FcRn: Structural insights for longer-lasting and more effective therapeutics. Crit. Rev. Biotechnol. 2015, 35, 235-254.

[36] Do, B. H.; Kang, H. J.; Song, J. A.; Nguyen, M. T.; Park, S.; Yoo, J.; Nguyen, A. N.; Kwon, G. G.; Jang, J.; Jang, M. et al.
Granulocyte colony-stimulating factor (GCSF) fused with Fc domain produced from E. coli is less effective than Polyethylene Glycol-conjugated GCSF. Sci. Rep. 2017, 7, 6480.

[37] Han, J. A.; Kang, Y. J.; Shin, C.; Ra, J. S.; Shin, H. H.; Hong, S. Y.;Do, Y.; Kang, S. Ferritin protein cage nanoparticles as versatile antigen delivery nanoplatforms for dendritic cell (DC)-based vaccine development. Nanomed. Nanotechnol. Biol. Med. 2014, 10, 561-569.

[38] Deshpande, S.; Masurkar, N. D.; Girish, V. M.; Desai, M.; Chakraborty, G.; Chan, J. M.; Drum, C. L. Thermostable exoshells fold and stabilize recombinant proteins. Nat. Commun. 2017, 8, 1442.

[39] Jeon, J. O.; Kim, S.; Choi, E.; Shin, K.; Cha, K.; So, I.; Kim, S. I.; Jun, E.; Kim, D. J.; Ahn, H. J. et al. Designed nanocage displaying ligand-specific peptide bunches for high affinity and biological activity. ACS Nano 2013, 7, 7462-7471.

[40] Georgiev, I. S.; Joyce, M. G.; Chen, R. E.; Leung, K.; McKee, K.; Druz, A.; Van Galen, J. G.; Kanekiyo, M.; Tsybovsky, Y.; Yang, E. $\mathrm{S}$. et al. Two-component ferritin nanoparticles for multimerization of diverse trimeric antigens. ACS Infect. Dis. 2018, 4, 788-796.

[41] Almine, J. F.; Bax, D. V.; Mithieux, S. M.; Nivison-Smith, L.; Rnjak, J.; Waterhouse, A.; Wise, S. G.; Weiss, A. S. Elastin-based materials. Chem. Soc. Rev. 2010, 39, 3371-3379.

[42] MacEwan, S. R.; Chilkoti, A. Elastin-like polypeptides: Biomedical applications of tunable biopolymers. Biopolymers 2010, 94, 60-77.

[43] Koria, P.; Yagi, H.; Kitagawa, Y.; Megeed, Z.; Nahmias, Y.; Sheridan, R.; Yarmush, M. L. Self-assembling elastin-like peptides growth factor chimeric nanoparticles for the treatment of chronic wounds. Proc. Natl. Acad. Sci. USA 2011, 108, 1034-1039.

[44] Wang, W.; Despanie, J.; Shi, P.; Edman, M. C.; Lin, Y. A.; Cui, H. G.; Heur, J. M.; Fini, M. E.; Hamm-Alvarez, S. F.; MacKay, J. A. Lacritin-mediated regeneration of the corneal epithelia by protein polymer nanoparticles. J. Mater. Chem. B 2014, 2, 8131-8141.

[45] Caliceti, P.; Veronese, F. M. Pharmacokinetic and biodistribution properties of poly(ethylene glycol)-protein conjugates. Adv. Drug Deliv. Rev. 2003, 55, 1261-1277.

[46] Qi, Y. Z.; Chilkoti, A. Protein-polymer conjugation-moving beyond PEGylation. Curr. Opin. Chem. Biol. 2015, 28, 181-193.

[47] Steiert, E.; Radi, L.; Fach, M.; Wich, P. R. Protein-based nanoparticles for the delivery of enzymes with antibacterial activity. Macromol. Rapid Commun. 2018, 39, 1800186.

[48] Grozdanovic, M.; Laffey, K. G.; Abdelkarim, H.; Hitchinson, B.; Harijith, A.; Moon, H. G.; Park, G. Y.; Rousslang, L. K.; Masterson, J. C.; Furuta, G. T. et al. Novel peptide nanoparticlebiased antagonist of CCR3 blocks eosinophil recruitment and airway hyperresponsiveness. J. Allergy Clin. Immunol. 2019, 143, 669-680.e12.

[49] Li, J. J.; Li, B.; Sun, J.; Ma, C.; Wan, S. K.; Li, Y. X.; Göstl, R.; Herrmann, A.; Liu, K.; Zhang, H. J. Engineered near-infrared fluorescent protein assemblies for robust bioimaging and therapeutic applications. Adv. Mater. 2020, 32, 2000964.

[50] Ma, C.; Li, B.; Zhang, J. R.; Sun, Y.; Li, J. J.; Zhou H. C.; Shen, J. L.; Gu, R.; Qian, J.; Fan, C. H. et al. Significantly improving the bioefficacy for rheumatoid arthritis with supramolecular nanoformulations. Adv. Mater. 2021, 33, 2100098.

[51] Song, Q. X.; Song, H. H.; Xu, J. R.; Huang, J. L.; Hu, M.; Gu, X.; Chen, J.; Zheng, G.; Chen, H. Z.; Gao, X. L. Biomimetic ApoEreconstituted high density lipoprotein nanocarrier for blood-brain barrier penetration and amyloid beta-targeting drug delivery. Mol. Pharm. 2016, 13, 3976-3987.

[52] Song, Q. X.; Huang, M.; Yao, L.; Wang, X. L.; Gu, X.; Chen, J.; Chen, J.; Huang, J. L.; Hu, Q. Y.; Kang, T. et al. Lipoprotein-based nanoparticles rescue the memory loss of mice with Alzheimer's disease by accelerating the clearance of amyloid-beta. ACS Nano 2014, 8, 2345.

[53] Kim, S. K.; Foote, M. B.; Huang, L. The targeted intracellular delivery of cytochrome $\mathrm{C}$ protein to tumors using lipidapolipoprotein nanoparticles. Biomaterials 2012, 33, 3959-3966.

[54] Lee, H. J.; Park, H. H.; Kim, J. A.; Park, J. H.; Ryu, J.; Choi, J.; Lee, J.; Rhee, W. J.; Park, T. H. Enzyme delivery using the 30Kc19 
protein and human serum albumin nanoparticles. Biomaterials 2014, 35, 1696-1704.

[55] Jiang, Y. Y.; Lu, H. X.; Chen, F.; Callari, M.; Pourgholami, M.; Morris, D. L.; Stenzel, M. H. PEGylated albumin-based polyion complex micelles for protein delivery. Biomacromolecules 2016, $17,808-817$.

[56] Pham, D. T.; Saelim, N.; Tiyaboonchai, W. Alpha mangostin loaded crosslinked silk fibroin-based nanoparticles for cancer chemotherapy. Colloids Surf. B Biointerf. 2019, 181, 705-713.

[57] Pham, D. T.; Saelim, N.; Cornu, R.; Béduneau, A.; Tiyaboonchai, W. Crosslinked fibroin nanoparticles: Investigations on biostability, cytotoxicity, and cellular internalization. Pharmaceuticals (Basel) 2020, 13, 86 .

[58] Wang, S. H.; Xu, T.; Yang, Y. H.; Shao, Z. Z. Colloidal stability of silk fibroin nanoparticles coated with cationic polymer for effective drug delivery. ACS Appl. Mater. Interfaces 2015, 7, 21254-21262.

[59] Kundu, J.; Chung, Y. I.; Kim, Y. H.; Tae, G.; Kundu, S. C. Silk fibroin nanoparticles for cellular uptake and control release. Int. J. Pharm. 2010, 388, 242-250.

[60] Bessa, P. C.; Balmayor, E. R.; Hartinger, J.; Zanoni, G.; Dopler, D.; Meinl, A.; Banerjee, A.; Casal, M.; Redl, H.; Reis, R. L. et al. Silk fibroin microparticles as carriers for delivery of human recombinant bone morphogenetic protein-2: In vitro and in vivo bioactivity. Tissue Eng. Part C Methods 2010, 16, 937-945.

[61] Wang, F.; Zhang, Y. Q. Bioconjugation of silk fibroin nanoparticles with enzyme and peptide and their characterization. Adv. Protein Chem. Struct. Biol. 2015, 98, 263-291.

[62] Kim, W. J.; Islam, R.; Kim, B. S.; Cho, Y. D.; Yoon, W. J.; Baek, J. H.; Woo, K. M.; Ryoo, H. M. Direct delivery of recombinant Pin1 protein rescued osteoblast differentiation of Pin1-deficient cells. $J$. Cell. Physiol. 2017, 232, 2798-2805.

[63] Huang, M.; Hu, M.; Song, Q. X.; Song, H. H.; Huang, J. L.; Gu, X.; Wang, X. L.; Chen, J.; Kang, T.; Feng, X. Y. et al. GM1-modified lipoprotein-like nanoparticle: Multifunctional nanoplatform for the combination therapy of Alzheimer's disease. ACS Nano 2015, 9, 10801.

[64] Zhang, Q.; Song, Q. X.; Gu, X.; Zheng, M. N.; Wang, A. T.; Jiang, G.; Huang, M.; Chen, H.; Qiu, Y.; Bo, B. et al. Multifunctional nanostructure RAP-RL rescues Alzheimer's cognitive deficits through remodeling the neurovascular unit. Adv. Sci. 2021, 8, 2001918.

[65] Wang, H. N.; Zou, Q.; Boerman, O. C.; Nijhuis, A. W. G.; Jansen, J. A.; Li, Y. B.; Leeuwenburgh, S. C. G. Combined delivery of BMP-2 and bFGF from nanostructured colloidal gelatin gels and its effect on bone regeneration in vivo. J. Control. Release 2013, 166, $172-181$

[66] Ortiz-Guerrero, J. M.; Polanco, M. C.; Murillo, F. J.; Padmanabhan, S.; Elías-Arnanz, M. Light-dependent gene regulation by a coenzyme $\mathrm{B}_{12}$-based photoreceptor. Proc. Natl. Acad. Sci. USA 2011, 108, 7565-7570.

[67] Wang, R.; Yang, Z. G; Luo, J. R.; Hsing, I. M.; Sun, F. B ${ }_{12}^{-}$ dependent photoresponsive protein hydrogels for controlled stem cell/protein release. Proc. Natl. Acad. Sci. USA 2017, 114, 5912-5917.

[68] Bessa, P. C.; Machado, R.; Nürnberger, S.; Dopler, D.; Banerjee, A.; Cunha, A. M.; Rodríguez-Cabello, J. C.; Redl, H.; Van Griensven, M.; Reis, R. L. et al. Thermoresponsive self-assembled elastin-based nanoparticles for delivery of BMPs. J. Control. Release 2010, 142, 312-318.

[69] Pokorski, J. K.; Hovlid, M. L.; Finn, M. G. Cell targeting with hybrid $\mathrm{Q} \beta$ virus-like particles displaying epidermal growth factor. ChemBioChem 2011, 12, 2441-2447.

[70] Matsumoto, R.; Hara, R.; Andou, T.; Mie, M. S. Y. S.; Kobatake, E. Targeting of EGF-displayed protein nanoparticles with anticancer drugs. J. Biomed. Mater. Res. B. 2014, 102, 1792-1798.

[71] Li, X.; Pan, C.; Sun, P.; Peng, Z. H.; Feng, E. L.; Wu, J.; Wang, H. L.; Zhu, L. Orthogonal modular biosynthesis of nanoscale conjugate vaccines for vaccination against infection. Nano Res. 2022, 15, 1645-1653.

[72] Raman, S.; Machaidze, G.; Lustig, A.; Aebi, U.; Burkhard, P. Structure-based design of peptides that self-assemble into regular polyhedral nanoparticles. Nanomed. Nanotechnol. Biol. Med. 2006,
2, 95-102.

[73] Pimentel, T. A. P. F.; Yan, Z.; Jeffers, S. A.; Holmes, K. V.; Hodges, R. S.; Burkhard, P. Peptide nanoparticles as novel immunogens: Design and analysis of a prototypic severe acute respiratory syndrome vaccine. Chem. Biol. Drug Des. 2009, 73, 53-61.

[74] Kanekiyo, M.; Wei, C. J.; Yassine, H. M.; McTamney, P. M.; Boyington, J. C.; Whittle, J. R. R.; Rao, S. S.; Kong, W. P.; Wang, L. S.; Nabel, G. J. Self-assembling influenza nanoparticle vaccines elicit broadly neutralizing $\mathrm{H} 1 \mathrm{~N} 1$ antibodies. Nature 2013, 499, 102-106.

[75] Marcandalli, J.; Fiala, B.; Ols, S.; Perotti, M.; De Van Der Schueren, W.; Snijder, J.; Hodge, E.; Benhaim, M.; Ravichandran, R.; Carter, L. et al. Induction of potent neutralizing antibody responses by a designed protein nanoparticle vaccine for respiratory syncytial virus. Cell 2019, 176, 1420-1431.e17.

[76] Boyoglu-Barnum, S.; Ellis, D.; Gillespie, R. A.; Hutchinson, G. B.; Park, Y. J.; Moin, S. M.; Acton, O. J.; Ravichandran, R.; Murphy, M.; Pettie, D. et al. Quadrivalent influenza nanoparticle vaccines induce broad protection. Nature 2021, 592, 623-628.

[77] Deng, L.; Mohan, T.; Chang, T. Z.; Gonzalez, G. X.; Wang, Y.; Kwon, Y. M.; Kang, S. M.; Compans, R. W.; Champion, J. A.; Wang, B. Z. Double-layered protein nanoparticles induce broad protection against divergent influenza A viruses. Nat. Commun. 2018, 9, 359.

[78] Lizotte, P. H.; Wen, A. M.; Sheen, M. R.; Fields, J.; Rojanasopondist, P.; Steinmetz, N. F.; Fiering, S. In situ vaccination with cowpea mosaic virus nanoparticles suppresses metastatic cancer. Nat. Nanotechnol. 2016, 11, 295-303.

[79] Lebel, M. È.; Daudelin, J. F.; Chartrand, K.; Tarrab, E.; Kalinke, U.; Savard, P.; Labrecque, N.; Leclerc, D.; Lamarre, A. Nanoparticle adjuvant sensing by TLR7 enhances $\mathrm{CD}^{+} \mathrm{T}$ cellmediated protection from Listeria monocytogenes infection. J. Immunol. 2014, 192, 1071-1078.

[80] Jovčevska, I.; Muyldermans, S. The therapeutic potential of nanobodies. BioDrugs 2020, 34, 11-26.

[81] Jiang, S. B.; Hillyer, C.; Du, L. Y. Neutralizing antibodies against SARS-CoV-2 and other human coronaviruses. Trends Immunol 2020, 41, 355-359.

[82] Xiang, Y. F.; Nambulli, S; Xiao, Z. Y.; Liu, H; Sang, Z; Duprex, W. P.; Schneidman-Duhovny, D.; Zhang, C.; Shi, Y. Versatile and multivalent nanobodies efficiently neutralize SARS-CoV-2. Science 2020, 370, 1479-1484.

[83] Lee, C.; Choi, M.; MacKay, J. A. Live long and active: Polypeptidemediated assembly of antibody variable fragments. Adv. Drug Deliv. Rev. 2020, 167, 1-18.

[84] Alam, M. K.; Brabant, M.; Viswas, R. S.; Barreto, K.; Fonge, H.; Ronald Geyer, C. A novel synthetic trivalent single chain variable fragment (tri-scFv) construction platform based on the SpyTag/SpyCatcher protein ligase system. BMC Biotechnol. 2018, $18,55$.

[85] Beck, A.; Goetsch, L.; Dumontet, C.; Corvaïa, N. Strategies and challenges for the next generation of antibody-drug conjugates. Nat. Rev. Drug. Discov. 2017, 16, 315-337.

[86] Govindan, S. V.; Cardillo, T. M.; Sharkey, R. M.; Tat, F.; Gold, D. V.; Goldenberg, D. M. Milatuzumab-SN-38 conjugates for the treatment of CD74+ cancers. Mol. Cancer Ther. 2013, 12, 968-978.

[87] Sandland, J.; Boyle, R. W. Photosensitizer antibody-drug conjugates: Past, present, and future. Bioconjugate Chem. 2019, 30, 975-993.

[88] Hoffman, R. M. The multiple uses of fluorescent proteins to visualize cancer in vivo. Nat. Rev. Cancer 2005, 5, 796-806.

[89] Guan, X. G.; Li, C.; Wang, D.; Sun, W. Q.; Gai, X. D. A tumortargeting protein nanoparticle based on Tat peptide and enhanced green fluorescent protein. RSC Adv. 2016, 6, 9461-9464.

[90] Matlashov, M. E.; Shcherbakova, D. M.; Alvelid, J.; Baloban, M.; Pennacchietti, F.; Shemetov, A. A.; Testa, I.; Verkhusha, V. V. A set of monomeric near-infrared fluorescent proteins for multicolor imaging across scales. Nat. Commun. 2020, 11, 239.

[91] Yu, D.; Baird, M. A.; Allen, J. R.; Howe, E. S.; Klassen, M. P.; Reade, A.; Makhijani, K.; Song, Y. Q.; Liu, S. M.; Murthy, Z. et al. 
A naturally-monomeric infrared fluorescent protein for protein labeling in vivo. Nat. Methods 2015, 12, 763-765.

[92] Zhang, J. R.; Li, B.; Zuo, J. L.; Gu, R.; Liu, B.; Ma, C.; Li, J. J.; $\mathrm{Liu}, \mathrm{K}$. An engineered protein adhesive with properties of tissue integration and controlled release for efficient cartilage repair. $A d v$. Healthc. Mater. 2021, 10, 2100109.

[93] Wang, S. D.; Li, B.; Zhang, H. L.; Chen, J. Y.; Sun, X.; Xu, J.; Ren, T.; Zhang Y. Y.; Ma, C.; Guo, W. et al. Improving bioavailability of hydrophobic prodrugs through supramolecular nanocarriers based on recombinant proteins for osteosarcoma treatment. Angew. Chem., Int. Ed. 2021, 60, 11252.

[94] Su, J. J.; Lu, S.; Jiang, S. J.; Li, B.; Liu, B.; Sun, Q. N.; Li, J. J.; Wang, F.; Wei, Y. Engineered protein photo-thermal hydrogels for outstanding in situ tongue cancer therapy. Adv. Mater. 2021, 33, 2100619

[95] Xiao, L. L.; Wang, Z. L.; Sun, Y.; Li, B.; Wu, B. H.; Ma, C.; Petrovskii V. S.; Gu, X. Q.; Chen, D.; Potemkin I. I. et al. An artificial phase-transitional underwater bioglue with robust and switchable adhesion performance. Angew. Chem., Int. Ed. 2021, 60, 12082-12089.

[96] Kobayashi, M.; Squires, G. R.; Mousa, A.; Tanzer, M.; Zukor, D. J.; Antoniou, J.; Feige, U.; Poole, A. R. Role of interleukin-1 and tumor necrosis factor $\alpha$ in matrix degradation of human osteoarthritic cartilage. Arthritis Rheum. 2005, 52, 128-135.

[97] Nuki, G.; Bresnihan, B.; Bear, M. B.; McCabe, D. Long-term safety and maintenance of clinical improvement following treatment with anakinra (recombinant human interleukin-1 receptor antagonist) in patients with rheumatoid arthritis: Extension phase of a randomized, double-blind, placebo-controlled trial. Arthritis Rheum. 2002, 46, 2838-2846.
[98] Shamji, M. F.; Betre, H.; Kraus, V. B.; Chen, J.; Chilkoti, A.; Pichika, R.; Masuda, K.; Setton, L. A. Development and characterization of a fusion protein between thermally responsive elastin-like polypeptide and interleukin-1 receptor antagonist: Sustained release of a local antiinflammatory therapeutic. Arthritis Rheum. 2007, 56, 3650-3661.

[99] Cai, R.; Chen, C. Y. The Crown and the Scepter: Roles of the protein corona in nanomedicine. Adv. Mater. 2019, 31, 1805740.

[100] Azizi, M.; Ghourchian, H.; Yazdian, F.; Bagherifam, S.; Bekhradnia, S.; Nyström, B. Anti-cancerous effect of albumin coated silver nanoparticles on MDA-MB 231 human breast cancer cell line. Sci. Rep. 2017, 7, 5178.

[101] Yousefpour, P.; Ahn, L.; Tewksbury, J.; Saha, S.; Costa, S. A.; Bellucci, J. J.; Li, X. H.; Chilkoti, A. Conjugate of doxorubicin to albumin-binding peptide outperforms aldoxorubicin. Small 2019, 15,1804452 .

[102] Schöttler, S.; Becker, G.; Winzen, S.; Steinbach, T.; Mohr, K.; Landfester, K.; Mailänder, V.; Wurm, F. R. Protein adsorption is required for stealth effect of poly(ethylene glycol)- and poly(phosphoester)-coated nanocarriers. Nat. Nanotechnol. 2016, 11, 372-377.

[103] Zhang, Z.; Guan, J.; Jiang, Z. X.; Yang, Y.; Liu, J. C.; Hua, W.; Mao, Y.; Li, C.; Lu, W. Y.; Qian, J. et al. Brain-targeted drug delivery by manipulating protein corona functions. Nat. Commun. 2019, 10, 3561.

[104] Chen, J. Q.; Qi, J.; Chen, C.; Chen, J. H.; Liu, L. J.; Gao, R. K.; Zhang, T. T.; Song, L.; Ding, D.; Zhang, P. et al. Tocilizumabconjugated polymer nanoparticles for NIR-II photoacousticimaging-guided therapy of rheumatoid arthritis. Adv. Mater. 2020, $32,2003399$. 